Aim We aimed to evaluate and improve compliance with:

- 'Facing The Future: Standards of Care in Emergency Settings' Standard 38: 'Infants, children and young people (ICYP) at high-risk of potential safeguarding presentations [eg. nonmobile infants with injuries] are reviewed by a senior (ST4+) paediatrician or PEM doctor'

- RCPCH Child Protection Companion, Section 5.4: Findings are consistent with history and development

Method We retrospectively audited notes of all infants $<1 \mathrm{yr}$ who presented to our Children's Emergency Department (CED) ( 28000 attendances/year) in September 2018 for compliance with above standards.

Cases were included if triage presentation suggested injury (eg. 'head injury', 'bruise', 'bite'); if presentation was unclear notes were reviewed to determine inclusion.

Results

- 359 attendances of under-1s (16\% of all attendances)

- 28 presented with an injury (8\% of all under-1 attendances)

Mean age was $5.6 \mathrm{~m}(10 \mathrm{~d}-10 \mathrm{~m})$

- $57 \%$ male

- Babies $<5$ months (considered fully immobile) accounted for a third

- $76 \%$ presented with head injury

Standards

- Standard 38-85\% compliance

- Consideration of history-39\%

- Consideration of development- 19\%

- Documentation of:

- Time of injury-76\%

- Social history- $23 \%$

- Clinical plan-100\%

Conclusion Though compliance with Standard 38 was good, other inadequacies in our current approach to infants with injuries were highlighted. Injury in infants, particularly head injury, is a common presentation to the CED. Our head injury proforma was felt to be unsuitable for use in infants; no 'infant injury proforma' exists.

To address this, we delivered departmental training and adapted our induction information. Furthermore, we developed and introduced a new 'Injuries in Under-1s' proforma. This includes additional space for documentation of reported injury mechanism and specifically addresses:

- Assessment of development/mobility

- Safeguarding screening questions

- Need for ST4+ review

Feedback from frontline staff suggests this aids both clinical and safeguarding decision-making. In order to complete the Plan-Do-Study-Act cycle we are currently in the process of re-audit.

\section{G483 SAFEGUARDING CHILDREN: ADDRESSING ORAL HEALTH NEEDS IN CHILD PROTECTION MEDICAL ASSESSMENTS}

${ }^{1} \mathrm{~S}$ Datta, ${ }^{1} \mathrm{~N}$ Lush, ${ }^{2} \mathrm{~A}$ Villis, ${ }^{2} \mathrm{C}$ Grayson. 'Department of Child Dental Health, Newcastle Dental Hospital, Newcastle upon Tyne, UK; ${ }^{2}$ Children and Young People Clinic, The Great North Children's Hospital, Newcastle upon Tyne, UK

10.1136/archdischild-2020-rcpch.414
Background Children with safeguarding concerns experience a greater incidence of untreated dental caries and trauma. The mouth is sometimes the focus of abuse or neglect and dental professionals are best placed to recognise oral signs of maltreatment. The oral health needs of children undergoing child protection medical assessments are often overlooked due to little interdisciplinary collaboration between paediatricians and the dental team. We present a holistic approach to addressing the medical and dental needs of these children.

Aim To establish oral health assessments for children undergoing child protection medical assessments

Standard All children over the age of 6 months should receive oral health assessments by a paediatric dentist during their child protection medical assessments

Method A local referral pathway was developed for paediatric dentists to attend child protection medical assessments and a dental appendix was created for standardised recording of information. All children received basic prevention via a tooth-brushing pack. This protocol was piloted on 20 children and modified based on feedback. Data were collected using a validated tool and analysed retrospectively.

Results $100 \%$ of child protection medical assessments met the standard and $49 \%$ of the children assessed had unmet dental needs. All children with unmet dental needs were successfully referred to the dental team for further management.

Recommendations Training and inclusion of Paediatric Dentistry registrars in child protection medical assessments and increased stakeholder engagement are crucial to maintain this initiative in the long-term.

Conclusion Our project has improved patient care and safety of children undergoing child protection medical assessments by enhancing teamwork with paediatricians and increasing the contribution of dental professionals to child protection.

\section{G484 THE CONTRIBUTION OF CHILD PROTECTION MEDICALS TO THE ASSESSMENT OF NEGLECT}

${ }^{1} \mathrm{~F}$ Blyth, ${ }^{2} \mathrm{~K}$ Davis, ${ }^{3}$ A Ramsbottom. ${ }^{1}$ Paediatrics, Barnsley Hospital NHS FT, Barnsley, UK; ${ }^{2}$ Paediatrics, Sheffield Children's Hospital NHS FT, Sheffield, UK; ${ }^{3}$ Child Assessment Unit, Sheffield Children's Hospital NHS FT, Sheffield, UK

\subsection{6/archdischild-2020-rcpch.415}

Aim To establish the main reasons children are referred for 'neglect medicals' and whether through these we are identifying additional unmet needs previously unrecognised and unaddressed in their social care/early help management plan.

Method Neglect is the most common form of child maltreatment but not a common indication for a child protection medical. The number of 'neglect medicals' conducted locally has increased, but we see nowhere near the number of children who are subject to neglect child protection plans. There is the impression that the request for these medicals comes once social care have been involved for some time, often when evidence is required for care proceedings. It is possible that there is an opportunity for earlier identification (and management) of needs.

All 'neglect medical' reports for children examined at a tertiary children's hospital within a six month time period (1/05/ 2018-31/10/2019) were reviewed. Follow up medicals and those where neglect was not the primary reason for referral were excluded. 
Results Of the 31 reports reviewed, 16 (52\%) of children were referred for concerns of physical neglect however there were often concerns regarding other unmet health needs. Following 'neglect medicals', new concerns regarding physical neglect were identified in $16(52 \%)$, emotional neglect in 6 (19\%), medical neglect in $6(19 \%)$, supervision in $5(16 \%)$, nutritional in $4(13 \%)$ and educational neglect in $3(9.6 \%)$ of children. For 11 (35\%) children, referrals were made for ongoing care. One child was admitted acutely. The legal status changed for 16 of the 24 children already known to social care.

Conclusion It is clear that although the majority of assessments done were for physical neglect, other categories of childhood neglect coexist. There is evidence to support further referrals by social care for assessment of children where there are concerns of neglect. Through early identification and intervention, the cumulative harmful effects of neglect can be minimised. This could be achieved via lowering the threshold for neglect medical assessments.

\section{G485 IMPLEMENTING GUIDELINES ON RADIOLOGICAL INVESTIGATIONS OF CHILDREN PRESENTING WITH SUSPECTED PHYSICAL ABUSE - IMPLICATIONS FOR PRACTICE}

L Shekhar, I Lakshminarayana. Paediatrics, The Royal Wolverhampton NHS Trust, Wolverhampton, UK

\subsection{6/archdischild-2020-rcpch.416}

Aim The new guidance on radiological investigations for suspected physical abuse brings clarity on investigations and sets recommendations for good practice. Adherence to this guideline ensures that occult injuries are diagnosed correctly and safeguarding decisions are made promptly and shared with multiagency partners thereby avoiding long hospital stays. However, this poses challenges to the radiology workforce in District General Hospitals as often there is a shortage of paediatric trained radiographers and radiologist.

This project aims to develop systems in place so this guideline is embedded in practice and to ensure compliance of this guideline.

Method A business case was developed to upgrade and improve the current provision of service delivered by the radiology department. A standard operating procedure for skeletal surveys ( SS) was developed. A retrospective audit of all radiological requests for skeletal surveys between April 2018 to September 2019 was completed to inform gaps in services and to implement change.

Results Twenty-five children had skeletal surveys during this period. Forty per cent of children were between 1-6 months of age with $20 \%$ of them being neonates. In over two thirds $(72 \%)$ of cases, SS was acquired within 24 hours and in over half (56\%) of cases reported within 24 hours. In over a quarter of cases $(28 \%)$ the report identified single fractures and in $8 \%$ of cases multiple fractures. Over threequarters of them $(76 \%)$ has repeat skeletal survey and reason for not repeating SS was due to clinical reasons or parents declining consent. A double reporting system where the initial reports completed by the local paediatric radiologist were then reviewed by the tertiary paediatric radiologist was established and up and running well. The average length of inpatient stay was 5 days. Documentation of consent was poor.

Conclusion We have demonstrated good compliance with the guidelines. Collaborative working between radiology and paediatrics has enabled to improve services and the care that we deliver to these vulnerable group of children. A consent form and patient information leaflet have been designed to address the issue of consent.

\section{G487(P) IS CLINICIAN GAZE AND BODY LANGUAGE ASSOCIATED WITH THEIR ABILITY TO IDENTIFY SAFEGUARDING CUES?}

${ }^{1} \mathrm{~A}$ Powell, ${ }^{2} \mathrm{~T}$ Collingwoode-Williams, ${ }^{3} \mathrm{~N}$ Schindler, ${ }^{2} \mathrm{SX}$ Pan, ${ }^{4} \mathrm{C}$ Fertleman. ${ }^{1}$ Medical School, University College London, London, UK; ${ }^{2}$ Department of Computing, Goldsmiths, London, UK; ${ }^{3}$ Paediatrics, Cambridgeshire Community Services NHS Trust, Cambridge, UK; ${ }^{4}$ Paediatrics/Undergraduate Education at UCL Medical School, Whittington Health Trust/ UCL, London, UK

\subsection{6/archdischild-2020-rcpch.417}

Aims Do GPs who undertake a covert child safeguarding virtual reality scenario use empathetic body language and look at the child in a parental consultation?

Methods This study used virtual reality consultations from 'A study of professional awareness using virtual reality: the responsiveness of GPs to child safeguarding cues'. These detail a consultation between a GP and a virtual reality avatar of a father and son. The behaviour of the father towards his son should elicit concern.

This study investigated whether the body language and gaze behaviour of the clinician was associated with their ability to identify safeguarding cues. Body language was measured in terms of head nod, body lean and eye contact, and gaze as the proportion of the consultation in which the clinician was looking at the child.

We conducted follow-up interviews with GP participants 18 months after the original study. These interviews covered their opinions of the study and virtual reality in general.

Consultations from 61 original participants were used, and 12 were interviewed.

Results There was a strong, statistically significant association $(\delta=0.606, \mathrm{p}<0.05)$ between empathetic body language and an ability to identify safeguarding cues. There was a weak, non-significant association $\left(\tau_{\mathrm{b}}=0.202, \mathrm{p}=0.06\right)$ between child-directed gaze and an ability to identify safeguarding cues.

At follow-up interview, some GPs felt that virtual reality was a useful training tool as it was more accessible than traditional training with actors. There was a consensus that the current iteration of the interface was not reactive enough, and that this was a barrier to interaction with the avatar and immersion in the consultation.

Conclusion This study has shown an association between empathetic body language and an ability to identify safeguarding cues within a simulated virtual reality consultation. Future prospective research could help determine why this association exists and if teaching in non-verbal communication skills can help to improve the recognition of safeguarding cues in clinical practice. It has also highlighted the use of virtual reality in paediatric safeguarding training, where child actors cannot be used, due to their age and the sensitivity of the scenario. 